\title{
A OCORRÊNCIA DE FEIÇÕES EROSIVAS COMO EVIDÊNCIA DA EVOLUÇÃO DE VOÇOROCA EM UBERLÂNDIA-MG
}

\author{
Eduardo Humberto Campos ${ }^{1}$ \\ Ricardo Reis Alves ${ }^{2}$ \\ Douglas Santana Serato ${ }^{3}$ \\ Silvio Carlos Rodrigues ${ }^{4}$
}

Artigo recebido em 18-09-2008 e aceito para publicação em 11-05-2009

\begin{abstract}
RESUMO
Esta pesquisa teve como objetivo investigar os processos pontuais de alterações do relevo e de outros acontecimentos que envolvam a área de estudo, localizada na Fazenda Experimental do Glória em Uberlândia-MG, identificar e catalogar as feições erosivas existentes no interior da voçoroca presente na área, bem como sua distribuição, compreender a evolução do processo erosivo, analisar os aspectos físico-químicos do solo e fazer levantamento dos aspectos fisionômicos da vegetação adaptada às condições deste ambiente. Os resultados obtidos indicaram que o solo desta área é composto em sua maior parte por seixos, seguido das areias, argilas e em menor grau pelo silte. Outra característica encontrada está relacionada ao $\mathrm{pH}$, que em toda a área caracteriza-se como ácido. No local o teor de matéria orgânica é baixo e a vegetação, quando presente é predominantemente rasteira. No total foram registradas 414 feições erosivas, predominando as fendas, alcovas de regressão, dutos de convergência e pontos e poças de ressurgência. Nota-se que as feições encontradas se concentram no médio curso da voçoroca onde se tem a maior evolução anual da erosão na área.
\end{abstract}

Palavras - chave: Cerrado, solos, impacto ambiental, erosão, dinâmica erosiva.

\begin{abstract}
The objectives of this research were to investigate the punctual process of relief alteration and other geophisical characteristics of the area, located in Glória Experimental Farm, Uberlândia MG. Other important aims of this paper were to identify and registry the erosion faces inside of a gully in this area, as well as its distribution, comprehend the erosion process evolution, to analysis some physical and chemical soil properties and study the conditions of the vegetation adapted to the conditions of this environment. The results obtained indicate that the soil of this area is composed, in large part, by groves, followed by sand, clay and silt. Other characteristic obtained is related to $\mathrm{pH}$, which shows acid values around all area. In this place, the quantity of organic matter is extremely low and the vegetation is predominantly with some bushes. It was registered 414 different erosion faces, with predomination of cracks, regression alcoves, pipes and points and puddles of the water resurgence. The erosion faces identified are concentrated in

\footnotetext{
${ }^{1}$ Graduando em Geografia pela Universidade Federal de Uberlândia (eduardoh.campos@yahoo.com.br)

${ }^{2}$ Doutorando em Geografia pela Universidade Federal de Uberlândia (ricardoreisalves@gmail.com)

${ }^{3}$ Graduando em Geografia pela Universidade Federal de Uberlândia (douglas.serato@gemail.com)

${ }^{4}$ Professor Doutor da Universidade Federal de Uberlândia (silgeo@ufu.br).
} 


\section{RBGF- Revista Brasileira de Geografia Física \\ Recife-PE Vol.1 n.02 Set/Dez 2008,64-77}

the median gully course, where was registered the upper annual evolution.

Key-words: Cerrado, Soil, Environment Impact, Erosion, Erosive dynamic.

\section{INTRODUÇÃO}

A crescente demanda de produtos agropecuários para exportação e abastecimento do mercado interno brasileiro tem acarretado expressivas mudanças no cenário agrícola do país. A cada dia mais áreas estão sendo ocupadas e submetidas a sistemas de manejo intensivos e tecnicamente avançados. O desmatamento de novas áreas para este tipo de atividade tem gerado grandes impactos ambientais, em especial relacionados à erosão de solos, que constituem um dos mais graves existentes hoje no país.

Um exemplo do exposto é o que ocorre hoje ao longo da bacia do Córrego Glória, localizada em Uberlândia - MG, que é tributário do Rio Uberabinha, principal reserva de abastecimento desta cidade. Tal bacia situa-se em uma área degradada por impactos ambientais relacionados à intensa erosão por voçorocas. A voçoroca estudada faz parte desta bacia, localizada na Fazenda Experimental do Glória (UFU) (Figura 1), e foi escolhida por se tratar de uma evolução desencadeada por ações antrópicas (desmatamento) e acelerada pela ação intempérica (chuvas principalmente).

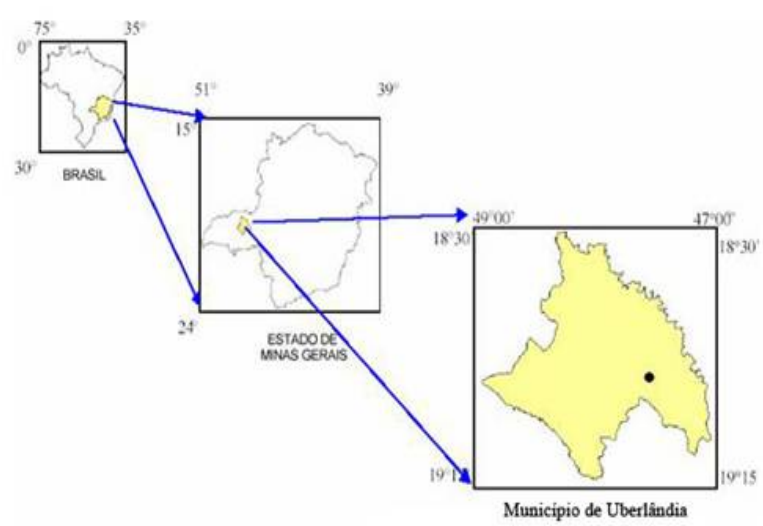

Figura 1: Mapa de Localização da Fazenda Experimental do Glória.

Fonte: SERATO, 2008.

A área de estudo localiza-se na região de contato geológico entre o Grupo Bauru e o Grupo São Bento, onde há predomínio de colinas sendo encontrado também tabuleiro como padrão de forma de relevo. Apresenta uma temperatura média anual de $23^{\circ} \mathrm{C}$, com uma pluviosidade variando entre $1300 \mathrm{~mm}$ a $1700 \mathrm{~mm}$, com verão quente e chuvoso e inverno seco, apresentando temperaturas mais amenas (Alves, 2007).

\section{MATERIAIS E MÉTODOS}

\section{Erosão}

Os estudos referentes a processos erosivos sempre requerem uma conceituação do que sejam sulcos, ravinas e voçorocas. Para não haver confusões quanto ao que cada conceito se refere, é necessário buscar uma 


\section{RBGF- Revista Brasileira de Geografia Física \\ Recife-PE Vol.1 n.02 Set/Dez 2008,64-77}

fundamentação teórica dos autores que trabalham na área de erosão de solos e assim tornar mais claro o que se entende por processos erosivos.

Voçoroca, segundo o novo dicionário geológico-geomorfológico, quer dizer:

[...] escavação ou rasgão do solo ou de rocha decomposta, ocasionada pela erosão do lençol de escoamento superficial. Nas regiões desmatadas como no vale do Paraíba (RJ e $\mathrm{SP}$ ), por exemplo, observa-se, por vezes, o aparecimento de grandes esbarracamentos de material decomposto, e de solos que são carregados pelas enxurradas. As voçorocas, quando em grande número e relativamente paralelas, dão aparecimento a verdadeiras áreas de badland, ou ainda área voçorocada. As voçorocas podem também ser formadas pelo escoamento subsuperficial. (GUERRA \& GUERRA, 2006, p. 637).

Porém o conceito de voçoroca é muito discutido entre pesquisadores da área geomorfológica, pois a dinâmica de fluxos de energia e matéria que ocorrem em áreas erosivas é complexa, obrigando do pesquisador uma observação em campo muito minuciosa dos processos erosivos para sua devida classificação.

A feição erosiva voçoroca é um estágio de um processo erosivo, que por sua vez ocorre geralmente na seqüência: canal preferencial, sulco, ravina e voçoroca. Muitas vezes a dificuldade em estabelecer a classificação de uma feição erosiva está no fato de que diversos processos estarem ocorrendo ao mesmo tempo. Portanto muitas feições erosivas podem estar se realizando em uma área ao mesmo tempo. Na própria área de estudo encontramos canais preferenciais seguidos de micro-ravinas que voltam a ser canal preferencial. Porém para quantificação e classificação de feições erosivas é necessário ter critérios, pois “a identificação dos mecanismos que determinam o processo erosivo é fundamental para elaboração de projetos de controle da erosão e devem ser cuidadosamente definida durante a etapa de cadastramento de processos erosivos em campo”. (DAEE/IPT, 1989 apud OLIVEIRA, 1999, p. 57).

A idéia de fluxos de matéria e energia é fundamental para entendermos como funcionam os sistemas naturais. "Quando um sistema natural (encosta, bacia hidrográfica, etc.) não é eficiente para dissipar a energia disponível, o sistema se adapta, de forma a atingir novo estado de equilíbrio” (BAK, 1997 apud OLIVEIRA, 1999, p. 58). Portanto em um sistema natural a busca por equilíbrio é sempre uma constante.

A capacidade que um sistema natural tem de dissipar energia está diretamente ligada as “características do sistema”, isto é, o uso do solo, cobertura vegetal, estruturação geológica, etc. Como a busca por equilíbrio é sempre uma constante em sistemas naturais, 


\section{RBGF- Revista Brasileira de Geografia Física \\ Recife-PE Vol.1 n.02 Set/Dez 2008,64-77}

então, quando há alteração nesse equilíbrio a busca de um novo equilíbrio dentro do sistema é evidente.

A “alteração das características do sistema” advém principalmente da atividade antrópica, que por vezes retira a cobertura vegetal, utilizam a área para agricultura ou pecuária, fazem estradas, cortam taludes, ou seja, alteram um sistema natural em equilíbrio desestabilizando-o. Essa alteração, no que se refere ao solo, pode vir a causar processos erosivos acelerados denominados ravinas e voçorocas. Portanto pode-se fazer a constatação de que ravinas e voçorocas estão intimamente ligadas a "atividade humana" que ao fazer intensivamente o uso da terra causa desequilíbrio no sistema natural, desencadeando a “erosão acelerada dos solos”.

Sabe-se, então, que ravinas e voçorocas são canais incisos naturais, porém a classificação que damos a esses processos diferencia-se na literatura geomorfológica e a diferenciação dessas erosões aceleradas pode ser variada. Algumas concepções como a do Instituto Paulista de Tecnologia (IPT) privilegia a qualidade, isto é, "ravinas seriam canais criados pela ação do escoamento superficial; e voçorocas, canais esculpidos pelo afloramento do lençol freático”
(CAVAGUTI, 1994; CANIL et al., 1995 apud OLIVEIRA,1999, p. 59).

Também se tem de cunho qualitativo (BACELLAR, 2006) onde diz que as características dos canais como sulcos são rasos com seção em V e com processo erosivo superficial, as ravinas são profundas com seção em $\mathrm{V}$ e com processo erosivo também superficial, enquanto que as voçorocas são profundas com seção em $U$ e com processo erosivo superficial e subsuperficial. Já outra concepção como a de GUERRA se apóia na quantidade, ou seja, "ravinas seriam incisões de até 50 centímetros de largura e profundidade. Acima desses valores, as incisões erosivas seriam denominadas de voçorocas” (GUERRA, 1998 apud OLIVEIRA, 1999, p. 59). Neste trabalho adotar-se-á como critério a definição quantitativa de GUERRA (1998).

\section{Feições erosivas}

A quantificação e a qualificação de feições erosivas, isto é, feições que marcam os solos em decorrência dos mecanismos erosivos são de fundamental importância quando se está estudando uma área erodida, já que essas podem indicar que processos estão ocorrendo e assim poder trabalhar na minimização da perda de solos. 


\section{RBGF- Revista Brasileira de Geografia Física}

Recife-PE Vol.1 n.02 Set/Dez 2008,64-77

\begin{abstract}
Sabendo que a observação dos mecanismos é rara, as feições erosivas adquirem um papel de testemunho dos mecanismos que ocorreram. A seguir tentarse-á associar as feições erosivas aos seus respectivos mecanismos de processos erosivos.
\end{abstract}

- Pedestais: “indicam a ocorrência de salpicamento intercalado com a remoção de partículas pelo escoamento superficial” (OLIVEIRA, 1999, p. 69);

- Caminhos preferenciais: indicam possíveis rotas de organização do escoamento superficial;

- Sulcos e Ravinas: “indicam as rotas de organização do escoamento superficial concentrado” (OLIVEIRA, 1999, p. 70);

- Voçoroca: indica as rotas do escoamento superficial e por vezes subsuperficiais;

- Alcovas de regressão: indicam "escoamento superficial na forma de filetes subverticais, quanto pela infiltração do lençol freático, ou ainda pela combinação desses dois mecanismos” (OLIVEIRA, 1999, p. 70);
- Filetes subverticais e escamamentos: indicam escoamento superficial. Pode ocorrer preferencialmente em paredes pouco coesas, porém também ocorre em solos de maior coesão, segundo Oliveira (1999);

- Dutos de convergência: indicam “interações entre erosão por queda d'água e eventuais ressurgências de zonas de saturação” (OLIVEIRA, 1999, p. 73). Costuma-se denominar erosão por pipes;

- Marmitas ou panelas: “indicam a atuação de erosão por queda d’água na base de taludes ou de degraus no interior de voçorocas" (OLIVEIRA, 1999, p. 73). Ainda podem ocorrer em áreas que contenham seixos e cascalhos onde os mesmos se fixam em depressões ao longo da área erodida e assim num processo de atrito esculpe a chamada marmita ou panela;

- Quedas de areia: indicam "liquefação espontânea de materiais inconsolidados e não coesivos” (OLIVEIRA, 1999, p. 73);

- Quedas de torrões: indicam "movimentos de massas associados, seja ao solapamento da base de taludes, seja ao desprendimento de 


\section{RBGF- Revista Brasileira de Geografia Física \\ Recife-PE Vol.1 n.02 Set/Dez 2008,64-77}

material ao longo de fendas de tração" (OLIVEIRA, 1999, p. 73/75);

- Costelas: “indicam variações, em profundidade, da resistência ao cisalhamento dos materiais de cobertura superficial” (NASCIMENTO, 1998 apud OLIVEIRA, 1999, p. 75). Podem ainda indicar ação de filetes subverticais e exfiltração do lençol freático;

- Fendas: “indicam a existência de movimentos generalizado da encosta em torno da incisão erosiva” (OLIVEIRA, 1999, p. 75);

- Pontos e Poças de ressurgência: “indicam área de ressurgência do lençol freático, ao longo de incisões erosivas” (OLIVEIRA, 1999, p. 77).

É importante destacar que este trabalho teve como foco principal identificar e catalogar as feições erosivas internas aos canais incisos (pedestais, alcovas de regressão, filetes subverticais e escamamentos, dutos de convergência, marmitas, quedas de areia, quedas de torrões, costelas, fendas e pontos e poças de ressurgência).

Para que os objetivos propostos fossem plenamente atingidos, esta pesquisa foi desenvolvida em três fases, sendo uma de gabinete, que consistiu em um levantamento bibliográfico prévio sobre erosão, uma de campo, para o entendimento, reconhecimento e cadastramento das feições erosivas existentes na área de estudo, coleta de amostras do solo do local, bem como para o levantamento dos aspectos fitofisionômicos da vegetação, e uma de laboratório, que consistiu em tratar os dados coletados.

\section{Trabalho de campo}

Para abranger toda a área de estudo foram realizados dois trabalhos de campo conduzidos no mês de fevereiro de 2008, a partir dos quais foram feitas a descrição e o catálogo das feições erosivas encontradas, coleta de amostras de solo do local e levantamento do porte vegetativo.

Para isso, foi empregada uma metodologia baseada na observação empírica. No primeiro trabalho de campo, para o catálogo das feições erosivas, fez-se a divisão da voçoroca em 3 áreas distintas: cabeceira, médio e baixo curso. Já no segundo trabalho, para a coleta de solos e levantamento dos aspectos fitofisionômicos da vegetação, afim de obter resultados mais detalhados, dividiuse a área em 6, a saber: margem direita e esquerda da cabeceria, margem direita e 


\section{RBGF- Revista Brasileira de Geografia Física \\ Recife-PE Vol.1 n.02 Set/Dez 2008,64-77}

margem esquerda médio curso e margem direita e margem esquerda baixo curso.

No primeiro trabalho de campo caminhava pela área fazendo a ủescriçção, o catálogo e a localização das feições erosivas encontradas em relação a primeira divisão elaborada para o local. No segundo trabalho, preenchia-se as fichas de campo elaboradas, que abordavam características como presença de seixos e a dimensão média desses, presença de laterita, presença de vegetação, porte vegetativo e coletava-se ainda amostras deste.

Ao término dos trabalhos de campo os dados foram levados ao laboratório, tratados e representados estatisticamente em softwares de geoestatística, e as amostras de solo submetidas a análises laboratoriais.

\section{Análises Laboratoriais}

A coleta de solo aplicada em campo permitiu a geração de 36 amostras. Elas foram submetidas a diversas análises laboratoriais relacionadas a suas propriedades físicoquímicas, como textura, teor de matéria orgânica e valor de pH. É importante destacar que a análise textural desenvolvida nesta pesquisa considerou a fração seixo como parte integrante do solo, pretendendo relacionar a presença destes com a existência de determinadas feições erosivas presentes no local.

Para determinar os valores de matéria orgânica do solo, valeu-se da metodologia citada por SILVA (1999), que adota o processo de calcinação por meio de mufla a $500^{\circ} \mathrm{C}$. Ao desenvolver essa metodologia, pesava-se 2 gramas de terra fina seca, e submetia-a a estufa a $105^{\circ} \mathrm{C}$ (peso inicial), de forma que toda a umidade da amostra era retirada. Após esta fase, as amostras eram colocadas na mufla e permaneciam ali por 5 horas. Após o resfriamento da mufla, cerca de 15 horas, cada amostra era pesada (peso final), e a diferença entre o peso inicial e o peso final representava o valor total de matéria orgânica presente no solo.

A metodologia de análise de $\mathrm{pH}$ das amostras de solo seguiu a técnica apresentada no Manual de Métodos de Análise de Solo da EMBRAPA (1997). Este método consiste na separação de $10 \mathrm{ml}$ de terra fina seca ao ar e adicionar $25 \mathrm{ml}$ de solução $\mathrm{KCl} 1 \mathrm{~N}$. Em seguida, mistura-se terra fina e $\mathrm{KCl} 1 \mathrm{~N}$, agitase a solução com um bastão de vidro e deixa a solução em repouso por 1 hora. Após o período de descanso, cada uma das amostras é agitada novamente e tem o seu valor de $\mathrm{pH}$ medido através de um pHmetro digital. 


\section{RBGF- Revista Brasileira de Geografia Física}

Recife-PE Vol.1 n.02 Set/Dez 2008,64-77

\section{RESULTADOS E DISCUSSÃO}

\section{Distribuição das Feições Erosivas}

Por meio dos trabalhos de campo realizados na área de estudo, verificou-se a existência de diversas feições no interior dos canais incisos, destacando-se pedestais, alcovas de regressão, filetes subverticais e escamamentos, dutos de convergência, marmitas, quedas de areia, quedas de torrões, costelas, fendas e pontos e poças de ressurgência.

As áreas onde ocorrem pedestais, filetes subverticais, escamamentos e queda de areia, foram reconhecidas, porém não contabilizadas devido ao alto grau de dificuldade em quantificá-las. No entanto verificou-se que sua ocorrência abrange todo o local de estudo.

No total, foram registradas 414 feições, sendo que destas as mais representativas foram as fendas, alcovas de regressão, costelas, pontos e poças de ressurgência e quedas de torrões, totalizando 92\% das feições encontradas (Tabela 1).

Tabela 1: Distribuição total das ocorrências por feição. Fonte: CAMPOS, 2008.

\begin{tabular}{|c|c|c|}
\hline \multicolumn{3}{|c|}{ TOTAL } \\
\hline $\mathbf{N}^{\mathbf{0}}$ & NOMENCLATURA & OCORRÊENCIAS \\
\hline $\mathbf{1}$ & Alcovas de regressão & 88 \\
\hline $\mathbf{2}$ & Costelas & 57 \\
\hline $\mathbf{3}$ & Dutos de convergência & 11 \\
\hline $\mathbf{4}$ & Fendas & 145 \\
\hline $\mathbf{5}$ & Marmitas ou panelas & 22 \\
\hline $\mathbf{6}$ & Pontos e poças de ressurgência & 56 \\
\hline $\mathbf{7}$ & Queda de torrões & 35 \\
\hline
\end{tabular}

Tal índice elevado de feições erosivas comprova a grande atividade existente no local, fato demonstrado pelos estudos desenvolvidos por Alves et al. (No prelo). Esses autores estimam que na última estação chuvosa e em dias sem chuva (2007/2008), houve uma perda média de 2,66 Kg/h de sedimentos do sistema.

Do total das feições, 30,9\% foram registradas na cabeceira, 57,5\% no médio curso e $11,6 \%$ no baixo curso. Para a primeira, as feições predominantes foram as fendas, com 48 ocorrências, alcovas de regressão com 36, pontos e poças de ressurgência, com 30 , seguidas por quedas de torrões, com 6 ocorrências.

Essa grande quantidade de feições geradas pela atuação do escoamento subsuperficial (pontos e poças de ressurgências e dutos de convergência) na cabeceira, em relação às demais áreas da voçoroca, retificam a afirmação feita por Alves (2007). Em seu trabalho esse autor afirma que o canal principal configura-se como o principal ponto de exudação do lençol freático.

No médio curso as feições mais importantes foram as fendas com 69 ocorrências, alcovas de regressão com 52, costelas com 35 ocorrências, pontos e poças de ressurgência e as quedas de torrões, com 


\section{RBGF- Revista Brasileira de Geografia Física \\ Recife-PE Vol.1 n.02 Set/Dez 2008,64-77}

26 registros cada. Registrou-se ainda 22 marmitas e 8 dutos de convergência.

Pode se destacar que essas grandes quantidades de feições encontradas nessas áreas, causadas por chegada de escoamento superficial no sistema, dão idéia do grande volume deste gerado na área de estudo. Outro fato relevante está relacionado a maior ocorrência de feições erosivas estar situada no médio curso, fato relacionado com $\mathrm{o}$ diagnóstico efetuado por Leal et al. (No prelo). Em seus estudos envolvendo o acompanhamento da evolução dos processos erosivos por meio do estaqueamento da área, os autores afirmam que a margem direita desta faixa apresenta as maiores taxas de evolução, com uma média evolutiva de 19,1cm em um período de 6 meses (entre agosto de 2007 e janeiro de 2008) enquanto a média para as outras áreas apresentou valores da ordem de $12,5 \mathrm{~cm}$ para o mesmo período. Já para o baixo curso, as feições que obtiveram o maior número de registros foram as fendas e as costelas (Tabela 2).

Tabela 2: Distribuição das ocorrências por feição para o baixo curso da área. Fonte: CAMPOS, 2008

\begin{tabular}{|c|c|c|c|}
\hline \multicolumn{3}{|c|}{ BAIXO CURSO } \\
\hline $\mathbf{N}^{\mathbf{0}}$ & NOMENCLATURA & OCORRÊECIAS & REPRESENTATIVIDADE (\%) \\
\hline $\mathbf{1}$ & Alcovas de regressão & 0 & 0 \\
\hline $\mathbf{2}$ & Costelas e depressões & 17 & 35,5 \\
\hline $\mathbf{3}$ & Dutos de convergência & 0 & 0 \\
\hline $\mathbf{4}$ & Fendas & 28 & 58,3 \\
\hline $\mathbf{5}$ & Marmitas ou panelas & 0 & 0 \\
\hline $\mathbf{6}$ & Pontos e poças de ressurgência & 0 & 0 \\
\hline $\mathbf{7}$ & Queda de torrões & 3 & 6,2 \\
\hline
\end{tabular}

\section{Características do solo e vegetação}

No alto curso da margem direita há uma grande concentração de seixos como fração predominante no solo, representando 55\% do total, seguida das frações areia, argila e silte, com valores médios por amostra de, respectivamente, 33\%, 7\% e 5\% (Tabela 3). Os seixos encontrados apresentam um diâmetro médio de 15 mm, com presença de laterita, e a vegetação, quando existente, é de porte rasteiro. $\mathrm{O}$ pH apresentou um valor médio de 4,46, variando entre 4,04 e 5,46 e a matéria orgânica entre $1,50 \%$ e 3,50\%, com valor médio de 2,50\%.

Tabela 3: Distribuição textural do solo para margem direita alto curso. Fonte: CAMPOS, 2008.

\begin{tabular}{|c|c|c|c|c|}
\hline \multirow{2}{*}{$N^{\circ}$ DA AMOSTA } & \multicolumn{4}{|c|}{ TOTAL } \\
\cline { 2 - 5 } & ARGILA NA AMOSTRA \% & SILTE NA AMOSTRA \% & AREIA NA AMOSTRA \% & SEIXOS NA AMOSTRA \% \\
\hline $\mathbf{1}$ & 8,22 & 9,48 & 28,99 & 53,31 \\
\hline
\end{tabular}


RBGF- Revista Brasileira de Geografia Física

Recife-PE Vol.1 n.02 Set/Dez 2008,64-77

\begin{tabular}{|l|c|c|c|c|}
$\mathbf{2}$ & 9,3 & 13,15 & 27,55 & 50 \\
\hline $\mathbf{3}$ & 4,7 & 2,81 & 38,61 & 53,88 \\
\hline $\mathbf{4}$ & 7,34 & 1,35 & 33,51 & 57,8 \\
\hline $\mathbf{5}$ & 6,77 & 3,15 & 33,77 & 56,31 \\
\hline $\mathbf{6}$ & 2,74 & 0,28 & 37,18 & 59,8 \\
\hline
\end{tabular}

No médio curso da margem direita, há também uma concentração elevada de seixos no solo, apresentando valores extremos de $50 \%$ e $75,76 \%$, seguida da fração areia, argila e silte (Figura 2). Os seixos encontrados neste local apresentam um diâmetro médio de 4,25 mm. Observouse que nesta área há presença de laterita, e quanto a vegetação, há pouca ocorrência, geralmente com porte rasteiro. Quanto à matéria orgânica, verificou-se que esta apresentou um valor médio de 3,13\% e em relação ao $\mathrm{pH}$ esse permaneceu entre 3,95 e 4,69 caracterizando solos ácidos, típicos de ambientes de Cerrado.

Essas características encontradas, grande teor de seixos e areia, pouca vegetação, demonstram a alta vulnerabilidade desta área à erosão, evidenciada pela grande ocorrência de feições erosivas neste local.

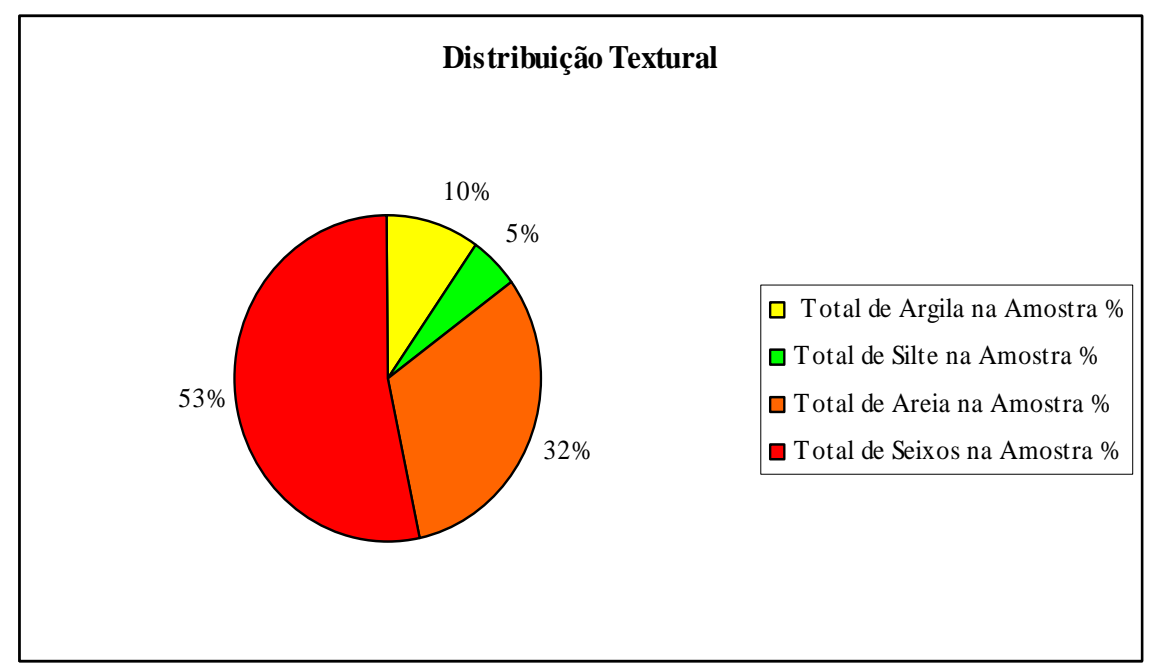

Figura 2: Frações texturais do solo para margem direita médio curso. Fonte: CAMPOS, 2008.

Quanto ao baixo curso verificou-se que as características existentes são semelhantes as dos outros segmentos da margem direita, com predominância de seixos na composição do solo seguida das areias, argila e silte.

O diâmetro dos seixos variou entre 4,50 $\mathrm{mm}$ e $25 \mathrm{~mm}$, com presença de laterita, e, diferente das demais áreas desta margem, a 


\section{RBGF- Revista Brasileira de Geografia Física \\ Recife-PE Vol.1 n.02 Set/Dez 2008,64-77}

vegetação é bem desenvolvida, apresentando os três estratos (rasteiro, arbustivo e arbóreo). Em relação à matéria orgânica presente no solo verificou-se que o teor foi 9\%, possivelmente pela presença dos três estratos vegetativos. Quanto ao $\mathrm{pH}$ este variou entre 3,82 e 4,30, caracterizando solos ácidos.

No alto curso da margem esquerda, verificou-se que não há presença de seixos e laterita, predominando a fração areia, tendo como valor médio $80,8 \%$ do total, seguida das frações argila e silte. Neste local há presença de vegetação rasteira e arbustiva. Os valores de matéria orgânica variam entre $2 \%$ e $3 \%$, e os de $\mathrm{pH}$ entre 4,21 e 4,28 . A não existência de seixos se dá ao fato de o solo do local recobrir a camada de seixos da formação Marília, localizada a alguns metros abaixo, que aflora em toda a margem direita e no médio e baixo curso da margem esquerda, enquanto que em relação à laterita, sua ausência se dá pela erosão à qual esta foi submetida ao longo do tempo.

Para o médio curso da margem esquerda, a fração do solo predominante foi a seixos com diâmetro médio de $3,80 \mathrm{~mm}$, seguida pelas frações areia, argila e silte (Tabela 4). Nota-se que neste local há presença de laterita e a vegetação possui porte arbustivo e rasteiro. Quanto à matéria orgânica verificouse que esta apresentou valores variando entre $2 \%$ e $2,5 \%$, sendo o menor encontrado em toda a área, e pH, entre 4,30 e 4,31.

Tabela 4: Distribuição textural do solo para esquerda médio curso.

Fonte: CAMPOS, 2008.

\begin{tabular}{|c|c|c|c|c|}
\hline $\begin{array}{c}\mathbf{N}^{\circ} \mathbf{D A} \\
\text { AMOSTRA }\end{array}$ & ARGILA NA AMOSTRA \% & SILTE NA AMOSTRA \% & AREIA NA AMOSTRA \% & SEIXOS NA AMOSTRA \% \\
\hline $\mathbf{1}$ & 10,23 & 0,85 & 38,81 & 50,11 \\
\hline $\mathbf{2}$ & 8,44 & 2,47 & 33,97 & 55,19 \\
\hline $\mathbf{3}$ & 7,44 & 1,18 & 34,88 & 56,51 \\
\hline $\mathbf{4}$ & 7,94 & 2,18 & 38,29 & 51,59 \\
\hline $\mathbf{5}$ & 7,22 & 2,32 & 32,67 & 57,79 \\
\hline
\end{tabular}

No baixo curso da margem esquerda o solo é constituído em sua maior proporção por seixos, com diâmetro médio de 36,67 mm, seguida das frações areia, argila e silte. Neste local foi verificada a presença de laterita e vegetação rasteira-arbustiva em toda a área. A matéria orgânica do solo apresentou um valor médio de 3,67\%, enquanto que para o $\mathrm{pH}$ esse valor foi de 4,11. 


\section{RBGF- Revista Brasileira de Geografia Física}

Recife-PE Vol.1 n.02 Set/Dez 2008,64-77

\section{CONSIDERAÇÕES FINAIS}

Por meio deste trabalho foi possível entender, de maneira geral, a dinâmica dos processos erosivos em ambientes de Cerrado, bem como as feições geradas pelos mecanismos erosivos. Além disso, permitiu o levantamento de diversos aspectos da área de estudo e a formação de um banco de dados a partir destas informações.

Verificou-se que em quase toda a área de estudo, com exceção do alto curso da margem esquerda, há presença de laterita e seixos, com este último predominando como fração presente no solo. No local há pouca cobertura vegetal, predominando áreas sem vegetação e com vegetação rasteira. Apesar disso, a matéria orgânica no solo permaneceu dentro do padrão de áreas de Cerrado, com média de 3\%. Neste mesmo sentido, o pH também ficou dentro da média, apresentando um valor de 4,3, caracterizando solos ácidos, típicos deste tipo de ambiente.

Essas características deste local fazem com que este seja altamente vulnerável a erosão, fato evidenciado pela grande quantidade de feições erosivas catalogadas. Nota-se que as feições encontradas se concentram no médio curso, onde tem-se a maior evolução anual da erosão na área. A partir dessas informações, conclui-se que em áreas onde há ocorrência de erosão por voçorocamento, tem-se o maior desenvolvimento anual onde predominam as feições fendas, alcovas de regressão, costelas e quedas de torrões.

Devido o lençol freático exfiltrar em diversos pontos da voçoroca e este não ser abastecido por outro curso d'água, este pode ser considerado perene, e de primeira ordem. Tais características dificultam o controle dos processos erosivos, visto que mesmo em épocas de seca tem-se a retirada de sedimentos provenientes da esculturação das feições erosivas pelo fluxo constante de água existente neste canal.

Desta maneira pode-se afirmar que este estudo foi fundamental para compreender as particularidades, similaridades e diferenças existentes neste local, bem como as características da paisagem e sua configuração. Não obstante a isso as informações levantadas nesta pesquisa servirão de referência para outros estudos relacionados a esta temática.

\section{REFERÊNCIAS}

ALVES, R. R.; ALVES, R. R.; RODRIGUES, S. C.. Dinâmica de Sedimentos em Canal de Voçoroca Durante a Estação Seca: Estudo de Caso na Cidade de Uberlândia-MG. In: SIMPÓSIO NACIONAL DE GEOMORFOLOGIA e ENCONTRO SUL-AMERICANO DE GEOMORFOLOGIA, V e I., 2004, Santa Maria - RS. Anais: Geomorfologia e Riscos 
Ambientais. Santa Maria - RS : UFSM, 2004. CD-ROM.

ALVES, R. R.; ALVES, R. R.; RODRIGUES, S. C. - Mapa geomorfológico dinâmico da Bacia Hidrográfica do Córrego Lagoinha. In: SIMPÓSIO NACIONAL DE GEOMORFOLOGIA, 4., 2002, São Luís. Anais. São Luís: UFMA, 2002.

ALVES, R. R, Monitoramento dos Processos Erosivos e da Dinâmica Hidrológica e de Sedimento de uma Voçoroca: estudo de caso na Fazenda do Glória na zona rural de Uberlândia-MG. Março 2007, 121p., Dissertação de Mestrado. IGUFU, Uberlândia, abril 2007.

ALVES, R. R, Monitoramento evolutivo de seções transversais em Voçoroca. Análise estatístico - morfométrico de perda de solo, no município de Uberlândia-MG. Março 2005, 106p., Dissertação de Mestrado. IGUFU, Uberlândia, abril 2005.

ALVES, R. R.; SERATO, D. S.; CAMPOS, E. H.; SILVA, J. F.; RODRIGUES, S. C. Evolução de Voçoroca em Região Tropical e a Criação de Ferramentas para Avaliação de seus Impactos. No prelo.

EMBRAPA. Manual de métodos de análises de solo. $2^{\circ}$ edição. Rio de Janeiro: EMBRAPA-CNPS, 1997. p. 212.

FAO (Food and Agriculture Organization). Técnicas de gerência do runoff para o controle da erosão e o conservação da umidade do solo. Disponível em: http://www.fao.org/docrep/T1696E/t1696e0 2.htm. Acesso em: 20 ago 2004.

FILIZOLA, H. F. Compactação e erosão do solo. In: HAMMES, V. S. (Org.). Julgar, percepção do impacto ambiental. $1^{\text {a }}$. Ed.
Brasília: Embrapa Informação Tecnológica, 2002. p 38-39.

HUDSON, N. W. Reconnaissance methods. In: Field measurement of soil erosion and runoff. Bedford United Kingdon: Silsoe Associates Ampthill, 1993. (Food and Agriculture Organization of the United Nations Rome, 1993). Disponível em: $<$ http://www.fao.org/documents/show_cdr.asp? url_file=/docrep/T0848E/T0848E00.htm >. Acesso em: 23 jun. 2003.

IONITA, I. Hydraulic efficiency of the discontinuos gullies. Catena. AmsterdamNetherlands, v. 50, p.369-379, jan. 2003. Número Especial.

LEAL, P. C. B.; SILVA, A. H. da; PINESE JÚNIOR, J. F.; ANDRADE, I. F. de; RODRIGUES, S. C. Monitoramento Erosivo Através de Estaqueamento. Fazenda Experimental do Glória. No prelo.

LEOPOLD, L. B. Channel Form and Process. In: Fluvial process in geomorphology. 2ed. Nova York: Dover publications, 1995. p 151195.

OYGARDEN, L. Rill and gully development during an extreme winter runoff event in Norway. Catena. Amsterdam-Netherlands, v. 50, p.217-242, jan. 2003. Número Especial.

OLIVEIRA, M. A. T. de. Processos erosivos e preservação de áreas de risco de erosão por voçorocas. In: GUERRA, A. J. T.; SILVA, A. S. da; BOTELHO, R. G. M. (Org). Erosão e Conservação dos solos: conceitos, temas e aplicações. 1. ed. Rio de Janeiro: Bertrand Brasil, 1999. p 57-99.

POESEN, J.; NACHTERGAELE, J.; VERSTRAETEN, G.. Gully erosion and environmental change: importance and research 


\section{RBGF- Revista Brasileira de Geografia Física \\ Recife-PE Vol.1 n.02 Set/Dez 2008,64-77}

needs. Catena. Amsterdam-Netherlands, v. 50, p.91-133, jan. 2003. Número Especial.

ROCHA, E. A. V. - Avaliação do Processo Evolutivo e da Dinâmica Erosiva: Um estudo de Caso no Municipio de Ipameri. Fev. 2007, 114p., Mestrado, Instituto de Geografia, UFU, Uberlândia, Março 2007.

SILVA, Alexandre C.; TORRADO, Pablo V.; JUNIOR, José de S. A. Métodos de Quantificação da Matéria Orgânica do Solo. Revista da Universidade de Alfenas, v. 5, p. 21-26, 1999.

SILVA, A. M. da; SHULZ, H. E.; CAMARGO, P. B. de. Erosão e Hidrossedimentologia em Bacias Hidrográficas. 1. ed. São Carlos - SP: RIMA, 2003. 140p.

SOIL SCIENCE SOCIETY OF AMERICA, 2001. Glossary of Soil Science Terms. Madison, (WI): Soil Science Society of America. Disponível: $<$ http://www.soils.org/sssagloss/. Acessado em: 20 ago 2004.

TORRI, D.; BORSELLI, L. Equation for high-rate gully erosion. Catena. Firenze, Itália, v. 50, n. 2-4, p. 449-467, jan. 2003. 